\title{
A TOOLBOX FOR SIMULATION-BASED OPTIMIZATION OF SUPPLY CHAINS
}

\author{
Christian Almeder \\ Margaretha Preusser \\ Department of Business Administration, University of Vienna \\ Brünner Str. 72 \\ A-1210 Vienna, Austria
}

\begin{abstract}
In this paper we present a general framework for simulating and optimizing the operational decisions in a supply chain network. We developed a supply chain network library for the simulation software AnyLogic (C XJ Technologies) and a linearized version as an optimization model implemented using XpressMP (C) Dash Optimization). Aggregated results for the simulation experiments are fed into the optimization model. The solution of the optimization model is used to improve operational decision in the supply chain. In order to gain good results this process is repeated until a stable solution is reached. This approach enriches the simulation framework by a powerful tool to improve the supply chain by simultaneously optimizing a large number of possible decisions.
\end{abstract}

\section{INTRODUCTION}

Discrete-event simulation and (mixed-integer) linear programming are widely accepted methods for analyzing and improving supply chain networks. But both approaches have crucial drawbacks: Simulation models are often to complex to apply an effective optimization technique. Optimization models are mostly too abstract, such that the relation to real-world scenarios is questionable.

We present a newly developed toolbox for simulating operational decisions such as production, stocking, transportation, and distribution within a large supply chain network assuming that a central planning is applicable. In addition, we developed a general optimization model representing a simplified version of the simulation model. This linearization is used to gain improved decisions which allow to operate the supply chain at low cost within a stochastic environment (cf. Preusser et al. 2005a and 2005b).

Most of today's simulators include possibilities to do a black-box parameter optimization of a simulation model. But Swisher et al. (2000) and Fu (2002) show that so far implemented methods are very rudimentary.
In the field of supply chain simulation Kleijnen (2005) gives a short overview of simulation tools and techniques used for supply chains. He distinguishes between four different approaches: spreadsheet simulation, system dynamics, discrete-event dynamic systems simulation, and business games. For discrete-event simulation numerous software packages are available. Some are very specialized for a specific part of the supply chain and others offer a general framework with a high functionality in modeling and visualization of supply chains (cf. Kelton, Sadowski, and Sadowski 2002; Kuh and Rabe 1998; Stäblein, Baumgärtel, and Wilke 2007).

There are a few papers on combinations of simulation and optimization in the context of supply chains. Truong and Azadivar (2003) developed an environment for solving supply chain design problems, where they combine simulation with genetic algorithms and mixed-integer programs. But they remain on a strategic level with the questions of facility location and partner selection.

The most related work by Lee and Kim (2002) shows a real combination of simulation and optimization for the case of a production-distribution system. They use simulation to check the capacity assumptions for a simpler linear model in a more realistic environment and to update these capacity parameters for the optimization. After several iterations they end up with a solution of the optimization model which is also within the constraints of the stochastic simulation model. Their method is quite similar to our approach, but they aim for more realistic capacity estimation for the optimization model, whereas we try to find a robust plan for production, stocking, and transportation considering stochastic and nonlinear operations and costs.

\section{MODELING APPROACH}

The main idea is to represent the supply chain as a discrete-event model (D-E model) and as a linear, deterministic optimization model. At first we perform several simulation runs in order to get basic information about the 
mean and the variances of the parameters (e.g. unit transportation costs) which are then fed into the linear model. For these first simulation runs user-defined decision rules for operating the supply chain network are used. After solving the linear model the result is transformed into decision rules and is used in the discrete-event model. Now we start again with several simulation experiments in order to verify our first parameter estimations and, if necessary, to update them for further optimization steps (see Figure 1).

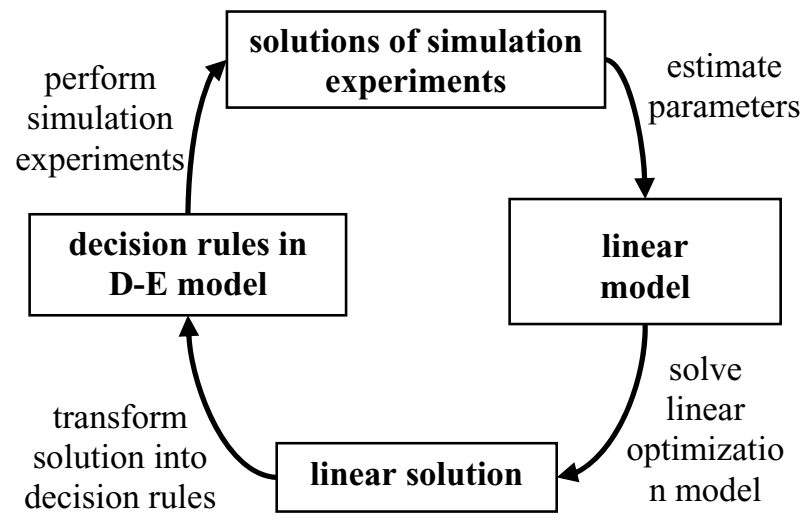

Figure 1: Interaction between simulation and optimization.

In order to couple the linear model and the simulation model, we first have to define, which kind of data and how it should be exchanged. We store all necessary information in a database:

- general network structure

- general parameters used in the simulation and linear model

- $\quad$ results of the linear model (= parameters for the simulation)

- $\quad$ results of the simulation model (= parameters for the linear program)

The simulation model is designed as the master process, which controls the data communication and the LP/MIP-solver used for solving the linear optimization model. The simulation model and the optimization model retrieve values from the database and store values in it using the Open Database Connectivity (ODBC) interface.

\section{ANYLOGIC TOOLBOX}

The simulation model is implemented using AnyLogic (C) XJ Technologies), a Java-based simulation tool. The model is constructed as a library including several different modules. These modules represent the four types of participants in the supply chain network:

- $\quad$ suppliers providing raw materials;
- customers who demand certain products at a specific time;

- production/transfer sites where production, stocking, and transshipment takes place.

- transportation connections between members of the supply chain.

Furthermore, we need a special control module necessary for controlling the simulation experiments as well as organizing the communication with the LP/MIP-model which was developed in parallel using XpressMP. This linear model is a simplified deterministic version of the library modules of the simulation model. In this section we will explain the different modules of our supply chain network.

\subsection{Module Supplier}

This module is used to generate certain products, store them, and deliver them if demanded. It has one input port to receive orders for products and one output port to send out products. If this module receives an order through the input port, it sends the requested amount of products via the output port. If the amount exceeds the current inventory level, only the available amount is sent. As soon as new products arrive in the inventory they are delivered until the whole order has been fulfilled. The costs arising in this module are only inventory costs for storing products prior to delivery. These costs may have any userdefined functional form. The products generated in this module per period are assumed to be given (cf. Figure 2).

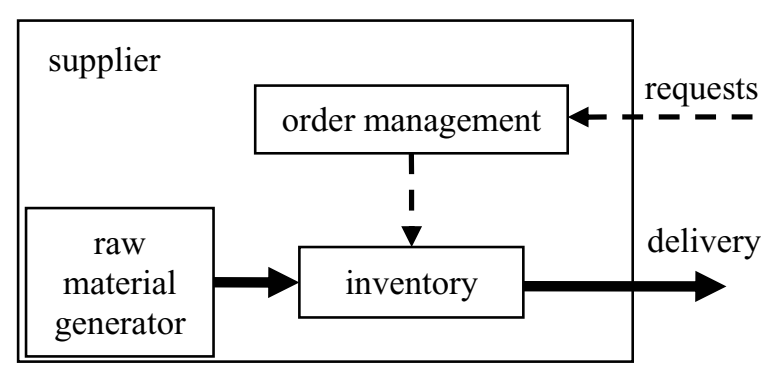

Figure 2: Logical structure of the supplier module (dashed arrows indicate information flow, solid arrows indicate material flow)

We developed a simplified representation as a linear model (see Appendix A). This linear model aggregates the user-defined holding cost and use it as a product-specific linear cost factor in the linear model in (1).

\subsection{Module Production}

This module is the core of the whole model. It represents a production site as well as a transfer point. It consists of an input and an output storage. Items are either transformed into new items or simply transferred to the output 


\section{Almeder and Preusser}

storage. This module has one input port and one output port for orders, as well as one input and one output port for products. The input storage is replenished by ordering products via the output port for orders from a supplier or another production module. The ordering policy may be either autonomous (e.g. an $(\mathrm{s}, \mathrm{S})$-policy or any userdefined policy) or it is determined by the result of the linear model. Products are received through the product input port and stored in the input inventory. The production of new products or the transfer of products is initiated by an order placed by the output inventory. The delay for production and transfer is a user-defined function. It may contain stochastic elements and depend on other parameters (e.g. the current load). Production and transfer have limited capacities and furthermore production is restricted to the availability of raw materials. If these capacities do not allow producing (or transferring) a lot as a whole, it is split into several batches. Through the input order port the module receives orders from other production or customer modules. Products are sent through the output product port according to these orders and based on availability. Costs arise in this model for inventory holding (input and output), for production, and for transfer (cf. Figure 3).

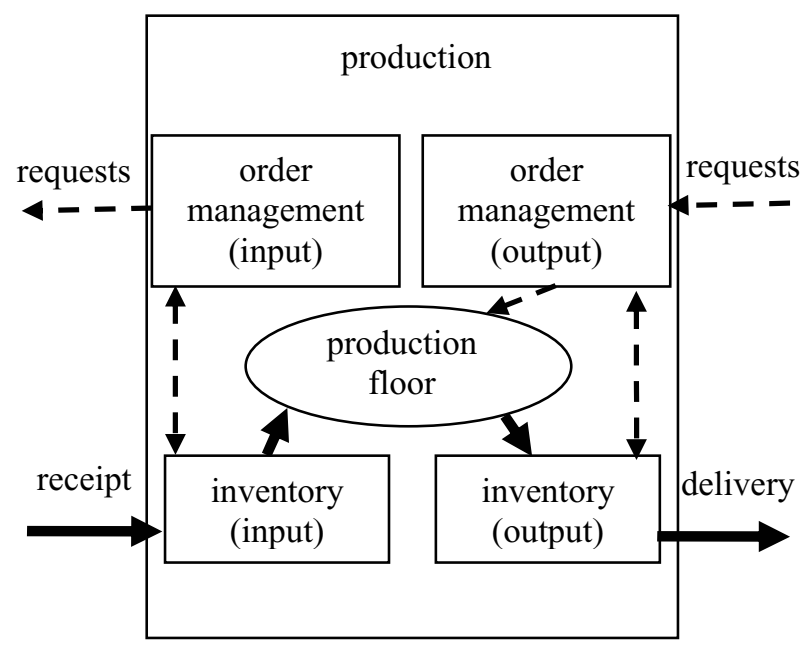

Figure 3: Logical structure of the production module

The simulation model and the linear model are connected through the cost factors for production and inventory in (1) as well as the production delays in (19) which are user-defined functions in the simulation model possibly containing stochastic and nonlinear elements. The resulting production and transfer amounts of the linear model are used to determine production plans in the simulation model.

\subsection{Module Customer}

According to a given demand table, the customer orders the products at the production sites. The customer has an input inventory, from which the demand is satisfied. The inventory level can be negative (shortages) as well as positive (oversupply). It has one output port for sending orders and one input port for receiving products. The orders are sent either according to the demand table (including a standard delay time for transportation) or according to the solution of the linear model. At this module shortage costs as well as penalty cost for positive inventory occur (cf. Figure 4).

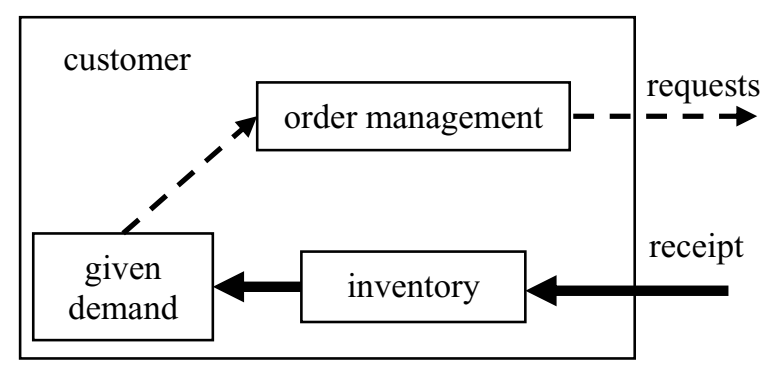

Figure 4: Logical structure of customer module

The relation between the simulation model and its linear representation is defined by the penalty cost factor in (1).

\subsection{Module Transport}

This module is used to transport products between different modules. It receives products through its single input port and sends it (according to some time delay) through the output port to the next module (Production or Customer). It has a limited capacity and organizes the transports according to a FIFO rule. It is also possible to split shipments if the available capacity does not allow single shipment. The user-defined time delay may be stochastic and may depend on other parameters. User-defined costs arise for finished transportation and may include transportation time, amounts, and fixed charge parts (cf. Figure 5).

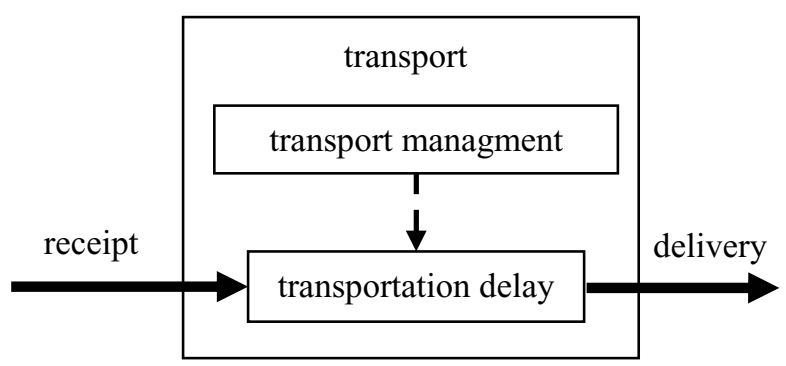

Figure 5: Logical structure of the transport module

The connection between the simulation and the optimization model is defined by the transportation cost factor in (1) and the transportation delay in (15) on one side, and by the transportation amounts on the other side. These 


\section{Almeder and Preusser}

transportation amounts are used to define ordering schemes in the simulation model.

\subsection{Modul SCMControl}

This module is necessary to control the simulation experiments and to administrate the data exchange the XpressMP via the ODBC interface. It allows to automate the search for optimized decision rules for the simulation model.

\section{RESULTS}

Implementing a simulation model in AnyLogic means to arrange the according modules and connect them. In Figure 6 an illustrative example shows, how these modules can be connected in order to maintain information flow (direct connections between Supplier, Production, and Customer) and material flow (via Transport modules). Furthermore the cost and delay functions for each module must be specified.

For the described experiments we use a supply chain as shown in Figure 7. This supply chain consists of 3 actors: a supplier, a producer, and a customer. For transportation of products two transport modules are used, which connect the supplier and the producer as well as the producer and the customer. Two types of products are demanded by the customer: product 1 which is provided by the supplier and sent via the intermediate to the customer and product 2 which is produced by the intermediate using product 1 as a raw material. The planning horizon covers 40 periods. The simulation model includes different kinds of nonlinear and stochastic elements described later. Using such an example we are able to compare our method also with exact deterministic approaches like a mixed-integer program. Thus we can verify that our method can be used to determine high quality solutions within a short time.

The first variation of our example considers stochas- tic transportation times as well as fixed costs per transport operation. Figure 7 shows the objective function values of both simulation and linear programming.

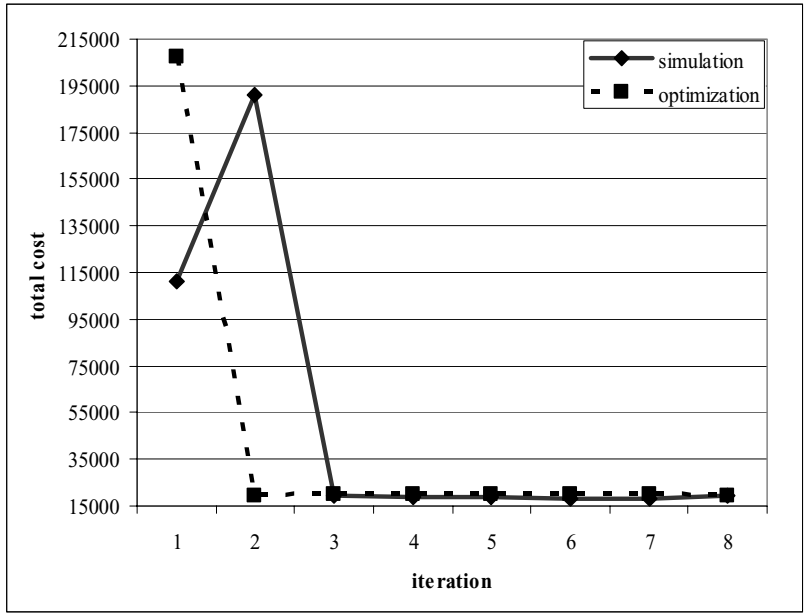

Figure 7: Objective values of the linear optimization model and the simulation model for each iteration for the first variation (stochastic, fixed cost for transportation).

We start with the simulation model using an autonomous rule for replenishing the inventories. Since we start with all inventories empty, it takes a long time, until the orders are fulfilled. This causes an overestimation of transportation and production delays. Therefore, the first solution of the linear model, which is then based on these extremely long delays, has an even higher objective value, mainly caused by penalty costs for late (or even no) deliveries. Consequently, the simulation model leads to a similar objective function in iteration 2 , because it uses the delivery plans of the solution of the linear model. Due to the fact that the solution of the linear model causes a somehow synchronized material flow, the measured delays are much lower now. Therefore, the solution of the linear model in the second iteration decreases tremendously. After three iterations the simulation and the LP-model converge to the same solution.

The second variation of the examples includes more

supplier

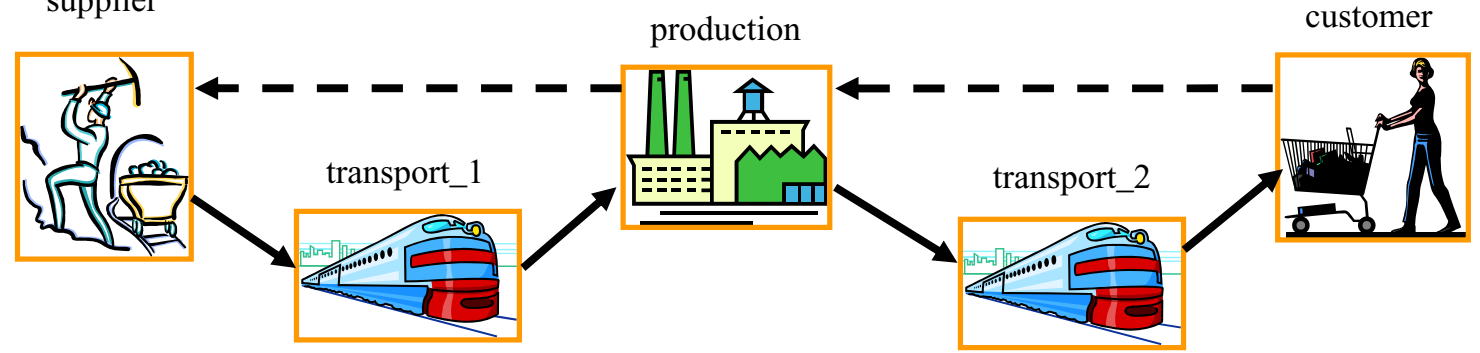

Figure 6: This figure shows an example of the module configuration for a simple supply chain consisting of 1 supplier, 1 production site, and 1 customer (dashed lines indicate request communication, solid lines indicate material flow 


\section{Almeder and Preusser}

nonlinear elements. Now the linear costs in production and transfer are extended with fix costs per production or transfer lot. Figure 8 shows the results for this case.

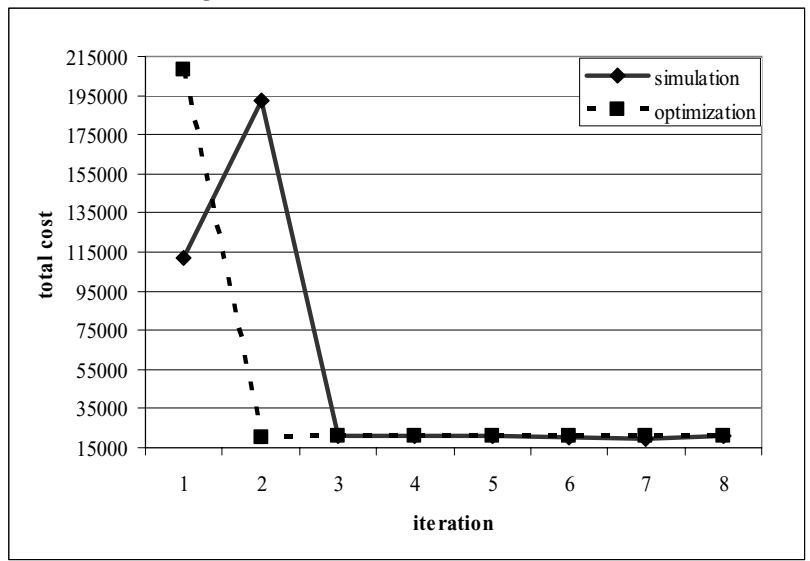

Figure 8: Objective values of the linear model and the simulation model for each iteration for the second variation (first variation and step function for production and transfer cost).

Again we can observe the same behavior of the solution in the first 2 iterations. After that both models converge to almost the same values. Differences are only caused by the stochastic behavior of the simulation model.

For the third variation we use transportation times which depend on the amount that is loaded. As it is shown in Figure 9 the total costs converge, but do not settle down on the same value as we have seen it in the previous examples. In fact, the cost of the solution of the linear model remains beyond the cost of the solution of the simulation. This can be explained by a kind of overestimation during the linearization step of the transportation delays. We assume that due to the lack of information the variability of the transportation delays is caused by a stochastic process. We use the $90 \%$-quantile for estimating the delay parameters, i.e. we use delay parameters such that in approximately $90 \%$ of the cases the delay is shorter. Hence, the transportation delays are overestimated during the linearization step and the linear model in most cases assumes longer transport times as the simulation model. This leads to some delayed deliveries and therefore to an increase in the penalty costs.

Based on conducted tests we may conclude that our method converges to a solution, as long as there are no extreme nonlinear properties, such as high fixed costs, or highly volatile stochastic elements. In order to verify the quality of these solutions we formulated an exact mixedinteger linear program which includes all nonlinear features of the simulation experiment. The stochastic parameters were substituted by deterministic estimations based on the distribution functions used in the simulation model. The solution of this MIP model and the solution of our optimizing approach was transformed into decision rules for the simulation model and 20 independent simulation runs were performed. On average our method reached a $3.3 \%$ better result.

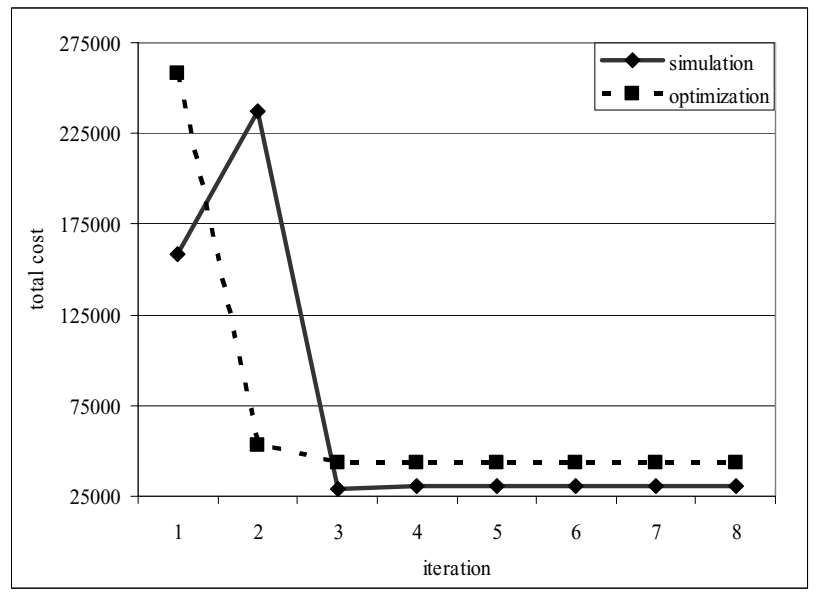

Figure 9: Objective values of the linear model and the simulation model for each iteration for the third variation (as second variation, but load-dependent delays instead of stochastic delays).

Finally we tested also larger supply chain networks including 3 suppliers, 4 production sites and 3 customers. This example includes nonlinear costs as well as stochastic production and transportation delays. Figure 10 shows again a fast convergence within 3-4 iterations.

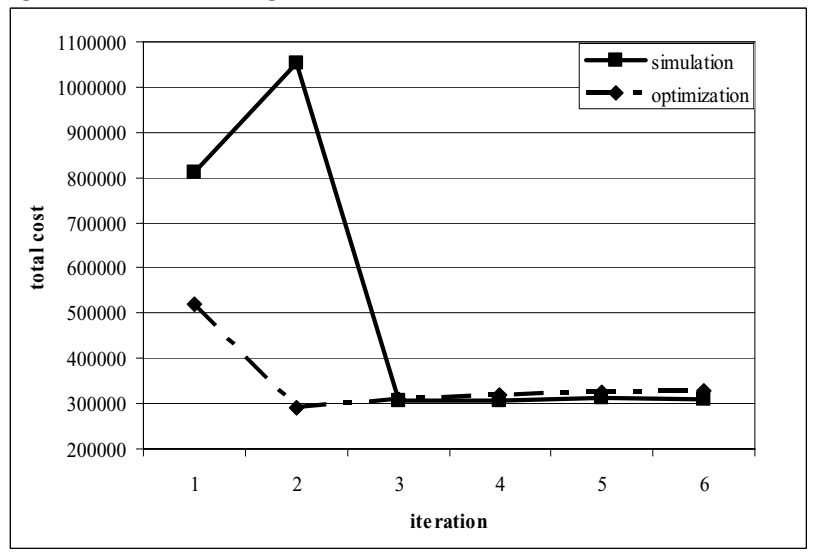

Figure 10: Objective values of the linear model and the simulation model for each iteration for a large supply chain network.

\section{CONCLUSIONS}

In this paper we have presented a useful approach for combining simulation models and linear programs. We have developed a general toolbox for simulating and analyzing the effects of operational decisions on a supply chain network. The toolbox allows to easily create simulation models for any kind of supply chain network structure. A special technique allows to include linear optimi- 


\section{Almeder and Preusser}

zation models into the simulation framework in order to improve decision rules.

A few illustrative examples indicate that this method is beneficial, because it combines the advantage of simulation models and of linear models, which leads to a more realistic planning environment for supply chain networks.

Further research will still be necessary for investigating the linearization step and the generation of new decision rules. For example, we may try to optimize the quantile used for the delay parameters. This may lead to general results about safety stock or safety time decisions in specific stochastic environments. Furthermore, more sophisticated decision rules based on the results and maybe also on a sensitivity analysis of the LP-solution are possible. We may think of adaptive decision rules which are able to compensate stochastic customer behavior.

So this approach opens a vast field of possible experiments and further investigations for improving supply chain networks with just using two well-established methods, namely linear programming and discrete-event simulation.

\section{A LINEAR OPTIMIZATION MODEL}

The linear supply chain model consists of $J$ locations, which can be separated into three subsets, i.e. the suppliers $J_{S}$, the intermediates $J_{0}$ and the customers $J_{C}$. Furthermore the model includes a set of products $\mathrm{P}$ and a set of transportation modes $V$. $T$ indicates the number of periods. The model implies three types of decision variables: ${ }^{v} x_{i j}^{p}(t), m_{i}^{p}(t)$. For the problem formulation we use the following notation:

$\begin{array}{ll}J & \text { set of locations } J=J^{s} \cup J^{o} \cup J^{c} \\ j \in J^{s} & \text { raw-material supplier (starting nodes) } \\ j \in J^{c} & \text { customer (end nodes) } \\ j \in J^{0} & \text { nodes between supplier and customer } \\ P & \text { set of products } \\ V & \text { set of transportation modes } \\ T & \text { number of periods } \\ { }^{v} x_{i j}^{p}(t) & \text { flow of product } p \text { from location } i \text { to location } \\ & j \text { with transportation mode } v \text { (sent away in } \\ & \text { period } t \text { ) } \\ m_{i}^{p}(t) & \text { amount of product } p \text { (product } p \text { is the end } \\ & \text { product of the production process at } \\ & \text { location } i \text { ), that starts to be produced at lo- } \\ & \text { cation } i \text { in period } t \\ u_{i}^{p}(t) & \text { amount of product } p, \text { that starts to be trans- } \\ & \text { acted in location } i \text { in period time } t \\ { }^{i n} f_{j}^{p}(t) & \text { amount of product } p \text {, arriving at location } j \\ & \text { in period } t\end{array}$

\begin{tabular}{|c|c|}
\hline${ }^{u t} f_{j}^{p}(t)$ & $\begin{array}{l}\text { amount of product } p \text {, sent away at location } j \\
\text { in period } t\end{array}$ \\
\hline${ }^{i n} l_{i}^{p}(t)$ & $\begin{array}{l}\text { inbound inventory level of product } \mathrm{p} \text { at lo- } \\
\text { cation } i \text { in period } t\end{array}$ \\
\hline${ }^{\text {out }} l_{i}^{p}(t)$ & $\begin{array}{l}\text { outbound inventory level of product } p \text { at lo- } \\
\text { cation } i \text { in period } t\end{array}$ \\
\hline$S_{j}^{p}(t)$ & supply of product $p$ at location $j$ in period $t$ \\
\hline${ }^{i n} h_{i}^{p}$ & $\begin{array}{l}\text { inbound inventory costs (per unit) for prod- } \\
\text { uct } p \text { at location i }\end{array}$ \\
\hline${ }^{\text {out }} h_{i}^{p}$ & $\begin{array}{l}\text { outbound inventory costs (per unit) for } \\
\text { product } p \text { at location } i\end{array}$ \\
\hline${ }^{i n} L_{i}(t)$ & $\begin{array}{l}\text { maximum capacity of inbound inventory at } \\
\text { location } i\end{array}$ \\
\hline${ }^{\text {out }} L_{i}(t)$ & $\begin{array}{l}\text { maximum capacity of outbound inventory } \\
\text { at location } i\end{array}$ \\
\hline${ }^{\text {invin }} \operatorname{Cap}^{p}{ }_{i}(t)$ & $\begin{array}{l}\text { maximum amount of product } p \text { that can be } \\
\text { held in the inbound inventory of interme- } \\
\text { diate } i \text { in period } t\end{array}$ \\
\hline${ }^{\text {invout }} \mathrm{Ca}$ & $\begin{array}{l}\text { maximum amount of product } p \text { that can be } \\
\text { held in the outbound inventory of interme- } \\
\text { diate } i \text { in period } t\end{array}$ \\
\hline${ }^{v} c_{i j}^{p}$ & $\begin{array}{l}\text { transportation costs (per unit) of product } p \\
\text { transported from location } i \text { to location } j \\
\text { with transportation mode } v\end{array}$ \\
\hline${ }^{v} C_{i j}(t)$ & $\begin{array}{l}\text { maximum transportation capacity of trans- } \\
\text { portation mode } v \text { on the way from location } i \\
\text { to location } j\end{array}$ \\
\hline${ }^{p r o d} C_{i}(t)$ & $\begin{array}{l}\text { maximum production capacity at location } i \\
\text { in period } t\end{array}$ \\
\hline${ }^{t a} C_{i}^{p}(t)$ & $\begin{array}{l}\text { maximum transaction capacity at location } i \\
\text { in period } t\end{array}$ \\
\hline${ }^{v} \operatorname{Cap}^{p}{ }_{i j}(t)$ & $\begin{array}{l}\text { amount of product } p \text { that transportation } \\
\text { mode } v \text { can transport from location } i \text { to lo- } \\
\text { cation } j\end{array}$ \\
\hline${ }^{\text {prod }} \operatorname{Cap}^{p}{ }_{i}(t)$ & $\begin{array}{l}\text { amount of product } p \text { that can be produced at } \\
\text { location } i \text { in period } t\end{array}$ \\
\hline${ }^{t a} \operatorname{Cap}^{p}{ }_{i}(t)$ & $\begin{array}{l}\text { amount of product } p \text { that can be transacted } \\
\text { at location } i \text { in period } t\end{array}$ \\
\hline$\delta_{i}^{p}$ & $\begin{array}{l}\text { amount of periods required to produce } \\
\text { product } p \text { at location } i\end{array}$ \\
\hline$\sigma_{i}^{p}$ & $\begin{array}{l}\text { amount of periods required to transact } \\
\text { product } p \text { at location } i\end{array}$ \\
\hline$\alpha_{i}^{p}\left(p^{\prime}\right)$ & amount of product $p^{\prime}$ required to produce \\
\hline
\end{tabular}




\section{Almeder and Preusser}

one unit of product $p$ at location $i$

$w_{i}^{p} \quad$ production costs of product $p$ at location $i$

$z_{i}^{p} \quad$ transaction costs of product $p$ at location $i$

$a_{i}^{p} \quad$ factor, indicating the amount of capacity units required to produce one unit of product $p$ at location $i$

$b_{i}^{p}(t) \quad$ amount of product $p$, which is already in production process in period 0 , and will be finished in period $t$ (or external increase of inventory)

$d_{i}^{p} \quad$ factor, indicating the amount of capacity units required to transact one unit of product $p$ at location $i$

${ }^{v} g^{p} \quad$ factor, indicating the amount of capacity units required to transport one unit of product $p$ with transportation mode $v$

$q_{i}^{p} \quad$ factor, indicating the amount of capacity units required to hold one unit of product $p$ at the inventory of location $i$

${ }^{v} \tau_{i j} \quad$ amount of periods required by transportation mode $v$ requires to go from location $i$ to location $j$

$\rho_{i}^{p} \quad$ penalty costs (per unit) at location $i$

$D_{i}^{p}(t) \quad$ demand for product $p$ at location $i$ in period $t$

$r_{i}^{p}(t) \quad$ amount of product $p$, which is already transported at period 0 , and will arrive at location $i$ in period $t$ (or external increase of inventory)

The problem is formulated as follows:

$$
\begin{aligned}
\min & \sum_{i j \in J} \sum_{p \in P} \sum_{t=1, . . T} \sum_{v \in V}{ }^{v} c_{i j}^{p} \cdot{ }^{v} x_{i j}^{p}(t) \\
& +\sum_{i \in J^{0}} \sum_{p \in P} \sum_{t=1, . . T} w_{i}^{p} \cdot m_{i}^{p}(t) \\
& +\sum_{i \in J^{0}} \sum_{p \in P} \sum_{t=1, . . T} z_{i}^{p} \cdot u_{i}^{p}(t) \\
& +\sum_{i \in J^{0}} \sum_{p \in P} \sum_{t=1, . . T}{ }^{i n} h_{i}^{p} \cdot{ }^{i n} l_{i}^{p}(t) \\
& +\sum_{i \in J^{0} \cup J^{s}} \sum_{p \in P} \sum_{t=1, . . T}{ }^{o u t} h_{i}^{p} \cdot{ }^{\text {out }} l_{i}^{p}(t) \\
& +\sum_{i \in J^{c}} \sum_{p \in P} \sum_{t=1, . . T} \rho_{i}^{p} \cdot\left(-{ }^{i n} l_{i}^{p}(t)\right)
\end{aligned}
$$

subject to

$$
\begin{aligned}
& \sum_{p \in P}{ }^{v} g^{p} \cdot{ }^{v} x_{i j}^{p}(t) \leq{ }^{v} C_{i j}(t) \\
& { }^{v} x_{i j}^{p}(t) \leq{ }^{v} \operatorname{Cap}_{i j}^{p}(t) \\
& \sum_{p \in P} a_{i}^{p} \cdot m_{i}^{p}(t) \leq{ }^{\text {prod }} C_{i}(t) \\
& m_{i}^{p}(t) \leq{ }^{\text {prod }} \operatorname{Cap}_{i}^{p}(t) \\
& \sum_{p \in P} d_{i}^{p} \cdot u_{i}^{p}(t) \leq{ }^{t a} C_{i}^{p}(t) \\
& u_{i}^{p}(t) \leq{ }^{t a} \operatorname{Cap}_{i}^{p}(t) \\
& { }^{\text {out }} l_{i}^{p}(t) \geq 0 \quad \forall i \in J^{s} \\
& { }^{\text {in }} l_{i}^{p}(t) \geq 0,{ }^{\text {out }} l_{i}^{p}(t) \geq 0 \quad \forall i \in J^{0} \\
& { }^{\text {in }} l_{i}^{p}(t) \leq 0 \quad \forall i \in J^{c} \\
& \sum_{p \in P} q_{i}^{p} \cdot{ }^{i n} l_{i}^{p}(t) \leq{ }^{i n} L_{i}(t) \quad \forall i \in J^{0} \\
& { }^{\text {in }} l_{i}^{p}(t) \leq{ }^{i n v i n} \operatorname{Cap}_{i}^{p}(t) \quad \forall i \in J^{0} \\
& \sum_{p \in P} q_{i}^{p} \cdot{ }^{\text {out }} l_{i}^{p}(t) \leq{ }^{\text {out }} L_{i}(t) \quad \forall i \in J^{0} \\
& { }^{\text {out }} l_{i}^{p}(t) \leq{ }^{\text {invout }} \operatorname{Cap}_{i}^{p}(t) \quad \forall i \in J^{0} \\
& { }^{\text {in }} f_{j}^{p}(t)=\sum_{\substack{i \in J \\
{ }^{v} \tau_{i j}<t}} \sum_{v \in V}{ }^{v} x_{i j}^{p}\left(t-{ }^{v} \tau_{i j}\right) \quad \forall j \in J^{0} \cup J^{c} \\
& { }^{\text {out }} f_{j}^{p}(t)=\sum_{i \in J} \sum_{v \in V}{ }^{v} x_{j i}^{p}(t) \quad \forall j \in J^{s} \cup J^{0} \\
& { }^{\text {out }} l_{i}^{p}(t)={ }^{\text {out }} l_{i}^{p}(t-1)-{ }^{\text {out }} f_{i}^{p}(t) \\
& +S_{i}^{p}(t) \quad \forall i \in J^{s} \\
& { }^{i n} l_{i}^{p}(t)={ }^{i n} l_{i}^{p}(t-1)+{ }^{i n} f_{i}^{p}(t) \\
& -\sum_{p^{\prime} \in P} \alpha_{i}^{p}\left(p^{\prime}\right) \cdot m_{i}^{p^{\prime}}(t) \\
& -u_{i}^{p}(t)+r_{i}^{p}(t) \quad \forall i \in J^{0} \\
& { }^{\text {out }} l_{i}^{p}(t)={ }^{\text {out }} l_{i}^{p}(t-1)-{ }^{\text {out }} f_{i}^{p}(t) \\
& +\chi_{t \geq \delta_{i}^{p}} \cdot m_{i}^{p}\left(t-\delta_{i}^{p}\right) \\
& +\chi_{t \geq \sigma_{i}^{p}} \cdot u_{i}^{p}\left(t-\sigma_{i}^{p}\right)+b_{i}^{p}(t) \quad \forall i \in J^{0} \\
& \chi_{t \geq \varepsilon}= \begin{cases}1 & t \geq \varepsilon \\
0 & t<\varepsilon\end{cases} \\
& { }^{\text {in }} l_{i}^{p}(t)={ }^{i n} l_{i}^{p}(t-1)+{ }^{i n} f_{i}^{p}(t) \\
& -D_{i}^{p}(t)+r_{i}^{p}(t) \quad \forall i \in J^{c} \\
& { }^{v} x_{i j}^{p}(t) \geq 0, m_{i}^{p}(t) \geq 0, u_{i}^{p}(t) \geq 0
\end{aligned}
$$

The overall goal, which is represented by the objective function (1), is to minimize the total costs. In princi- 


\section{Almeder and Preusser}

ple, there are four types of costs: transportation cost, production cost, transshipment cost, and inventory cost.

The objective function is minimized with respect to several constraints :

Constraints (2) and (3) ensure that given transport capacities for both the individual and the aggregated case are not exceeded.

Constraints (4) and (6) are similar to the capacity constraints. They state, that given production capacities, and given transshipment capacities are not exceeded. Constraints (5) and (7) impose individual upper bounds on transshipment or production at a certain intermediate.

Constraints (8) and (9) ensure the nonnegativity of all inventory levels of suppliers and intermediates. The inbound inventory level at customer nodes can only take negative values. This restriction is given in constraint (10). The inbound and outbound inventories at the intermediates are furthermore capacitated. These capacities are considered in constraints (11) and (13). Additionally there are capacity restrictions for each product itself, i.e. restrictions (12) and (14).

In order to calculate the total inflow or outflow at every node, auxiliary equations (16) and (17) have been included. Equations (18) to (20) represent the inventory balance equations for each node. The nonnegativity of the decision variables is ensured in constraint (21).

\section{REFERENCES}

Fu, M. C. 2002. Optimization for Simulation: theory vs practice. INFORMS Journal on Computing 14:192215.

Kelton, W. D., Sadowski, R. P., Sadowski, D. A. 2002. Simulation with Arena, 2nd edn. McGraw-Hill.

Kleijnen, J. P. C. 2005. Supply chain simulation tools and techniques: a survey. International Journal of Simulation \& Process Modelling 1:82-89.

Kuhn, A., Rabe, M. 1998. Simulation in Produktion und Logistik (Fallbeispielsammlung), Springer.

Lee, Y. H., Kim, S. H. 2002. Production-distribution in supply chain considering capacity constraints. Computers \& Industrial Engineering 43:169-190.

Preusser, M., Almeder, C., Hartl, R. F., Klug, M. 2005a. LP Modelling and simulation of supply chain networks. In: Supply Chain Managament und Logistik: Optimierung Simulation, Decision Support. ed. H. O. Günther, D.C. Mattfeld, L. Suhl. 95-114. PhysicaVerlag.

Preusser, M., Almeder, C., Hartl, R. F., Klug, M. 2005 b. Hybrid Supply Chain Modelling - Combining LPModels and Discrete-Event Simulation. In: ORP3 Operational Research Peripatetic Postgraduate Programme proceedings. ed. M. C. Maroto Álvarez, J. Alcaraz Soria, G. R. Ruiz, F. Crespo Abril, R.
Vallada. 163-170. ESMAP, S.L., Universidad Politécnica de Valencia.

Stäblein, T., Baumgärtel, H., Wilke, J. 2007. The Supply Net Simulator SNS: An artificial intelligence apporach for highly efficient supply network simulation. In: Management logistischer Netzwerke. ed. H.O. Günther, D. C. Mattfeld, L. Suhl. 85-110. PhysicaVerlag.

Swisher, J. R., Jacobson, S. H., Hyden, P. D., Schruben, L. W. 2000. A survey of simulation and optimization techniques and procedures. In: Proceedings of the 2000 Winter Simulation Conference. ed. J. A. Joines, R. R. Barton, K. Kang, P. A. Fishwick. 119-128.

Truong, T. H., Azadivar, F. 2003. Simulation based optimization for supply chain configuration design. In: Proceedings of the 2003 Winter Simulation Conference. ed. S. Chick, P. J. Sánchez, D. Ferrin, D. J. Morrice. 1268-1275.

\section{AUTHOR BIOGRAPHIES}

CHRISTIAN ALMEDER is assistant professor at the Department of Business Administration of the University of Vienna. His research interests are discrete-event simulation, combinatorial optimization, metaheurstics, and optimal control models in the context of production and logistic systems. His web page can be found via <www. univie.ac.at/bwl/prod>

MARGARETHA PREUSSER is PhD Student at the Department of Business Administration of the University of Vienna. Her research is focused on optimization of supply chain networks using linear programming and simulation. The combination of these well-established methods will be the main issue of her $\mathrm{PhD}$ thesis. A list of publications is accessible via <www. univie.ac.at/bwl/prod> 